\title{
Assessment of Thermal Embrittlement in Duplex Stainless Steels 2003 and 2205 for Nuclear Power Applications
}

\author{
J.D. Tucker ${ }^{a}$, M.K. Miller ${ }^{b}$, and G.A. Young ${ }^{c}$ \\ a'Oregon State University, 204 Rogers Hall, Corvallis, OR 97331, USA, julie.tucker@oregonstate.edu, \\ +1-541-737-5840, corresponding author \\ ${ }^{b}$ Oak Ridge National Laboratory, P.O. Box 2008, Oak Ridge, TN 37831-6139, USA, \\ millermk@ornl.gov, +1-865-574-4719 \\ ${ }^{c}$ Knolls Atomic Power Laboratory, P.O. Box 1072, Niskayuna, NY 12309, USA, \\ george.young.contractor@unnpp.gov, +1-518-395-7413
}

\section{Abstract}

Duplex stainless steels are desirable for use in power generation systems due to their attractive combination of strength, corrosion resistance, and cost. However, thermal embrittlement at intermediate homologous temperatures of $\sim 475^{\circ} \mathrm{C}$ and below, limits upper service temperatures for many applications. New lean grade duplex alloys have improved thermal stability over standard grades and potentially increase the upper service temperature or the lifetime at a given temperature for this class of material. The present work compares the thermal stability of lean grade, alloy 2003 to standard grade, alloy 2205 , through a series of isothermal agings between $260^{\circ} \mathrm{C}$ and $482^{\circ} \mathrm{C}$ for times between 1 and 10,000 hours. Aged samples were characterized by changes in microhardness and impact toughness. Additionally, atom probe tomography was performed to illustrate the evolution of the $\alpha-\alpha^{\prime}$ phase separation in both alloys at select conditions. Atom probe tomography confirmed that phase separation occurs via spinodal decomposition for both alloys and identified the presence of $\mathrm{Ni}$ Cu-Si-Mn-P clusters in alloy 2205 that may contribute to embrittlement of this alloy. The impact toughness model predictions for upper service temperature show that alloy 2003 may be viable for use in $288^{\circ} \mathrm{C}$ applications for 80 year service lifetimes based on a Charpy V-notch criteria of $47 \mathrm{~J}$ at room temperature. In comparison, Alloy 2205 should be limited to $260^{\circ} \mathrm{C}$ applications for the same room temperature toughness of $47 \mathrm{~J}$. 
Keywords: duplex stainless steels, $475^{\circ} \mathrm{C}$ embrittlement, spinodal decomposition, atom probe tomography

\subsection{Introduction}

Duplex stainless steels (DSS) comprise a unique class of materials that possess desirable properties of both the face-centered cubic (austenitic) and body-centered cubic (ferritic) phases within their microstructures. The ferrite and austenite phases are present in roughly equal volume fractions, typically ranging from $30-70 \%$ ferrite. Relative to their austenitic counterparts, DSS tend to have higher strength, higher toughness, improved corrosion resistance (especially to localized corrosion), and exceptional resistance to halide stress corrosion cracking [1, 2]. Additionally, their relatively low nickel content lowers the cost of these alloys and helps ensure price stability.

DSS are widely used in chemical processing, desalination, pulp and paper, storage, and transportation industries due to their high strength and good corrosion resistance [1]. Components commonly manufactured from DSS include storage tanks, pipes, pressure vessels, heat exchangers, seawater systems, rotors, and structural members. However, DSS have had little application in power generation industries, in part due to concerns with thermal embrittlement. The thermal embrittlement that limits broader applications of DSS generally occurs at temperatures between $204^{\circ} \mathrm{C}$ and $538^{\circ} \mathrm{C}$ with a peak embrittlement rate near $475^{\circ} \mathrm{C}$. The low temperature tail of this embrittlement curve is often poorly defined due to long aging times required to define its location, but is critical to enable the use of these steels for long term, elevated temperature applications of interest to the nuclear power industry. Thermal embrittlement in this temperature range typically occurs due to the precipitation of the Cr-rich $\alpha^{\prime}$ phase in the Fe-rich $\alpha$ matrix. This $\alpha$ - $\alpha^{\prime}$ phase separation occurs in the ferrite grains of DSS and can occur by either nucleation and growth or by spinodal decomposition, depending on alloy composition and aging temperature [3]. The $\alpha-\alpha^{\prime}$ phase separation results in hardening in the ferrite phase and a loss of toughness of the bulk material. 
There are a number of commercially available DSS alloys and there is evidence that lean grades of duplex are more resistant to thermal embrittlement than standard grades [3-5]. Lean grade alloys contain lower concentrations of $\mathrm{Cr}$ and $\mathrm{Ni}$ equivalent elements $(\mathrm{Cr}, \mathrm{Ni}, \mathrm{Mo}, \mathrm{Cu}, \mathrm{N}, \mathrm{C}$, etc.) than standard grades. Small changes in alloy composition can impact the kinetics of the embrittlement reactions in the ferrite phase [3]. Alloy 2003 (UNS S32003) is a lean grade DSS with low Cr and Ni equivalent compositions that make it a promising candidate for elevated temperature applications. Alloy 2205 (UNS S32205/S31803) is the most widely used DSS and is characterized as a standard grade alloy. The mechanisms and rates in which phase separation occurs in DSS alloys with different compositions is the focus of this paper.

This work characterizes the thermal stability of alloy 2003 via a series of isothermal agings, and compares it to the widely used alloy 2205 . Atom probe tomography (APT) is used to identify the transformation mechanism (nucleation and growth vs. spinodal composition) and to quantify segregation of solute species to the different phases. The degradation of mechanical properties with phase separation is characterized by impact toughness and microhardness testing. This data is compiled and fit using a form of a Kolmogorov-Johnson-Mehl-Avrami (KJMA) equation in order to extrapolate mechanical properties to times and temperatures relevant to reactor plant lifetimes.

\subsection{Experimental Details}

\subsection{Material}

Duplex stainless steel alloys 2003 and 2205 were procured from the same vendor in the form of 3.8 $\mathrm{cm}$ thick plates. Both alloys were solution annealed above $1010^{\circ} \mathrm{C}$ and water quenched. The alloy heats and compositions are provided in Table 1. Bulk compositions were provided by vendor certifications and supplemented with independent chemical analysis [6, 7]. Alloy 2205 is more solute rich in most elements than alloy 2003, with the primary difference in higher $\mathrm{Cr}, \mathrm{Ni}$, Mo, and $\mathrm{Cu}$ concentrations. Due to small alloying differences and similar processing, both alloy microstructures were $\sim 50 \%$ ferrite. The phase fraction does not change significantly during aging. 


\subsection{Isothermal Aging}

Alloys 2003 and 2205 were given a series of isothermal agings in air between $260^{\circ} \mathrm{C}$ and $538^{\circ} \mathrm{C}$ for times between 1 and 10,000 hours to study the thermal stability. The peak embrittlement rate for $\alpha$ - $\alpha^{\prime}$ phase separation occurs near $475^{\circ} \mathrm{C}$. Aging at higher temperatures can lead to $\sigma$ phase formation. Material was loaded into a hot furnace and air-cooled. The test matrix for the aging conditions and how they were analyzed is summarized in Tables 2 and 3. The shaded conditions denote APT analysis. The as-received condition of both alloys was also analyzed for impact toughness and microhardness.

\subsection{Impact Toughness}

Charpy V-notch impact specimens were machined in the transverse-short (T-S) orientation from the aged plate of both alloys. Two or three replicate tests were performed at each test temperature. The Charpy impact machine used was capable to NIST compliance up to $434 \mathrm{~J}$. Data above this impact energy is provided for information only. Impact testing procedures are in accordance with ref. [8].

\subsection{Microhardness}

Specimens were sectioned from isothermally aged plates, polished, and etched for microhardness testing. A minimum of 10 microhardness measurements were taken in the ferrite grains of each

specimen. Measurements were taken on the short-long (S-L) surface of the rolled plate and utilized a Vickers indenter with a $10 \mathrm{gf}$ load. This small load was necessary to avoid edge effects from grain boundaries in accordance with ASTM standards, ref. [9]. Additional measurements were taken to better characterize the uncertainty in the measurements. The sources of variability studied include specimen-to-specimen, day-to-day, test performer, and replicate measurement variability.

\subsection{Atom Probe Tomography}


APT was performed on both alloys aged at $427^{\circ} \mathrm{C}$ for times of $1,100,1000$, and 10,000 hours. Specimens were fabricated from the ferrite phase of each alloy, as evidenced by scanning electron microscopy on a mechanically ground and polished surface, by a standard focused-ion-beam-(FIB)based in-situ lift-out and annular milling method [10]. APT of the resulting needle-shaped specimens was performed with a CAMECA Instruments LEAP ${ }^{\circledR}$ 4000X HR local electrode atom probe. This instrument features an energy-compensating reflectron lens for improved mass resolution. The materials were analyzed in voltage mode with a specimen temperature of $50 \mathrm{~K}$, a pulse repetition rate of $200 \mathrm{kHz}$, a pulse ratio of 0.2 , and an ion collection rate between 0.5 and $2 \%$ ion per field evaporation pulse. Regions that exhibited any gallium enrichment from the FIB-based specimen preparation method were excluded from further analyses. Deconvolution of the ions within overlapping isobars of different elements (e.g., $\mathrm{Cr}_{54} / \mathrm{Fe}_{54}$ ) was performed based on the natural abundances of the elements.

\subsection{Analytical Procedure}

\subsection{Impact Toughness Curve Fitting}

Curve fits to the raw impact toughness were performed to facilitate interpretation of the test data and to help normalize the scatter in the data. Data sets with clear upper shelf energies used a hyperbolic tangent fit (provided in Equation 1), where, $E$, is the impact energy at a given test temperature $\left(T_{\text {test }}\right)$ and $A, B, C$, and $T_{0}$ are fitting constants. In the absence of a defined upper shelf, the data were fit with an exponential equation form (Equation 2), where $a_{1}, b_{1}$, and $x_{0}$ are fitting constants.

$$
\begin{array}{lr}
E\left(T_{\text {test }}\right)=A+B * \tanh \left[\frac{\left(T_{\text {test }}\right)-T_{0}}{C}\right], & \text { Equation } 1 \\
E\left(T_{\text {test }}\right)=\frac{a_{1}}{1+\exp \left[\frac{x_{0}-\left(T_{\text {test }}\right)}{b_{1}}\right]} . & \text { Equation } 2
\end{array}
$$




\subsection{Kolmogorov-Johnson-Mehl-Avrami Model}

In order to compare embrittlement rates, a model was fit to the data of each alloy. This model describes the impact toughness or microhardness as a function of isothermal aging time and temperature, allowing for long time extrapolations at temperature to simulate component lifetimes. Data from specimens isothermally aged at and below $482^{\circ} \mathrm{C}$ were isolated and fit using nonlinear regression analysis to quantify the effects of exposure time and temperature. The model used in this study has the form of a Kolmogorov-Johnson-Mehl-Avrami (KJMA) equation [11-15]. The KJMA expression is used to describe a variety of phase transformations and related phenomena, and has the following general form:

$S(t, T)=1-e^{-(k(T) t)^{n}}$,

Equation 3

where, $S(t, T)$ is a progress variable in terms of aging time, $t$, and temperature, $T$, that varies continuously from 0 to 1 as the transformation proceeds from start to completion. The time exponent, $n$, is known as the Avrami exponent, and typically relates to the nucleation and growth mechanism and the geometry of the newly growing phase. This parameter often assumes an integer value, though this is not always the case [16]. The term $k(T)$ is a kinetic coefficient, which is typically described by an Arrhenius form [12]:

$k(T)=k_{0} e^{\frac{-Q}{R T}}$.

Equation 4

In Equation $4, k_{0} k_{0}$ is the pre-exponential factor, $Q$ is the effective activation energy for the phase transformation, and $R$ is the universal gas constant ( $8.314 \mathrm{~J} / \mathrm{mol}-\mathrm{K})$.

The KJMA model is scaled by the maximum change in impact toughness or microhardness in order to relate the measured value to the phase transformation. This model assumes that the change in hardness or impact toughness is linearly related to the phase fraction transformed. The 
microhardness at any time and temperature can be described by Equation 5, where $H_{\max }$ is the maximum hardness obtainable due to the phase transformation and $H_{0}$ is the original hardness of the unaged material. The model thus has five adjustable parameters $\left(H_{\max }, H_{0}, k_{0} H_{\max }, Q\right.$, and $\left.n k_{0}\right)$, which are obtained from fitting to the microhardness data. It can be seen from Equation 5 that at time, $t=0, H(t, T)=H_{0} H(t, T)=H_{0}$, and in the limit $t \rightarrow \infty, H(t, T)=H_{\max }$. The model interpolates smoothly between initial and saturation hardness, with the hardening dependent on time and temperature.

$H(t, T)=H_{M a x}-\left(H_{M a x}-H_{o}\right) e^{-(k(T) t)^{n}}$

Equation 5

A similar model has been employed to show how impact energy at a given test temperature varies with aging time and temperature. Equation 6 below provides the analogous equation, where $E_{0} E_{0}$ is the initial (maximum) impact toughness energy at a given test temperature and $E_{\min } E_{0}$ is the minimum impact toughness energy. Both $E_{0} E_{0}$ and $E_{\min } E_{0}$ are determined by fitting to the impact toughness data. Equation 7 provides an expanded form of equation 6 . Note that in equation 7 , the activation energy $(Q)$ is in units of $\mathrm{kJ} / \mathrm{mol}$, time $(t)$ is in hours and temperature $(T)$ is in Kelvin.

$$
\begin{array}{ll}
E(t, T)=E_{\min }-\left(E_{\min }-E_{0}\right) e^{-(k(T) t)^{n}} & \text { Equation } 6 \\
E(t, T)=E_{\min }-\left(E_{\min }-E_{o}\right) \cdot \exp \left\{-\exp \left[n \cdot\left(\ln \left(k_{0}\right)-\frac{1000 \cdot \mathrm{Q}}{R \cdot T}+\ln (t)\right)\right]\right\} . & \text { Equation } 7
\end{array}
$$

\subsection{APT Analysis}

Phase separation of the ferrite phase into the Fe-rich ( $\alpha$ ) and Cr-rich ( $\alpha$ ') phases was detected by statistically comparing the experimental frequency distribution of the Cr contents of 100 ion blocks to the binomial distribution with the same average concentration. The extent of the phase separation was estimated by a maximum likelihood fit of the experimental frequency distribution to the Langer, Bar-on, Miller (LBM) model [17, 18]. 


\subsection{Results \& Discussion}

\subsection{Impact Toughness}

The $427^{\circ} \mathrm{C}$ Charpy V-notch impact toughness data for alloys 2003 and 2205 as a function of aging time are compared in Figure 1. The impact toughness data show that lean grade alloy 2003 outperforms alloy 2205 by retaining more toughness for a given aging time and temperature. Near the peak embrittlement temperature of $475^{\circ} \mathrm{C}$, alloy 2003 is often an order of magnitude better than alloy 2205. This is clearly demonstrated in Figure 1, where the impact toughness curves for alloy 2003 at 100 and 1000 hours are similar to the 2205 curves at 10 and 100 hours, respectively.

The data points in Figure 1 are fit with curves described by Equations 1 and 2. These curves help average out the scatter in the data and facilitate comparison between test temperatures. Note that the curve fits are only accurate within a test temperature range supported by the data and should not be extrapolated to higher temperatures, because the upper shelf energy is not defined for many timetemperature combinations. Impact toughness values estimated by the curve fits, not individual data points, are used for all further analysis presented in this work.

In order to better describe the embrittlement caused by the $\alpha-\alpha^{\prime}$ phase separation with aging time and temperature, the KJMA equation was fit to the impact toughness values at a specific test temperature $\left(20^{\circ} \mathrm{C}\right)$. Only data collected at or below the nose of the time-temperature-transformation (TTT) curve $\left(\leq 482^{\circ} \mathrm{C}\right)$ are used in the model to ensure the same kinetics (simple Arrhenius-type) are taking place in all data sets. The impact toughness surface fit at $20^{\circ} \mathrm{C}$ for both alloys as a function of aging time and temperature is shown in Figure 2. At short aging times and low temperatures, the impact toughness is at a maximum. The impact toughness drops off with longer aging times and higher temperatures (up to $482^{\circ} \mathrm{C}$ ) until almost no energy is absorbed upon impact (i.e., a complete lack of toughness). The estimated KJMA parameters and their approximate standard error to the sufaces in Figure 3 are provided in Table 4. Note that, the "as-received"' condition is included in Figure 2 and the 
KJMA analysis at an arbitrary time and temperature $\left(260^{\circ} \mathrm{C}, 0.1\right.$ hours $)$, where no change in material properties is expected.

A graphical representation of the goodness of fit between the model and the impact toughness data is shown in Figure 3. The data are evenly distributed about the 1:1 line illustrating good agreement between the data and the model. Note that, the scatter in the data increases as the toughness increases. This scatter indicates that the fitting should be used with caution, but the low values (with the least scatter) are of the most engineering significance.

The KJMA parameter estimates show that lean grade alloy 2003 has a higher initial impact toughness value $\left(E_{0}\right)$ and lower activation energy $(Q)$ and pre-factor $\left(k_{0}\right)$ compared to alloy 2205 , however, the error bars overlap for the activation energy. The activation energy is analogus to the activation energy of diffusion and contains contributions from vacany formation and migration for diffusion mediated phase transformations. The other parameters are similar between the two alloys. The Avrami exponent $(n)$ is near 0.5 for both alloys and corresponds to instantaneous nucleation and 1D diffusion controlled growth according to ref. [19].

The effect of aging time and temperature on the impact toughness of both alloys is shown in Figure 4. Since alloy 2003 has a higher initial impact toughness, it is tougher than alloy 2205 in the 40-80 year time window of interest for the nuclear power industry. For example, alloy 2003 maintains a minimum toughness of $47 \mathrm{~J}$ for $80+$ years at $288^{\circ} \mathrm{C}$, where alloy 2205 only maintains this toughness for 11 years. Alloy 2003 provides a considerable margin in toughness over alloy 2205, either in time or in upper service temperature. The upper service temperatures for both alloys as a function of component lifetime (in hot years), with the requirement to maintain a minimum impact toughness of 47 $\mathrm{J}$ at $20^{\circ} \mathrm{C}$, are provided in Table 5. 
The data in Table 5 indicate that alloy 2003 has higher upper service temperatures over the time considered. The upper service temperature of alloy 2003 is $\sim 30^{\circ} \mathrm{C}$ higher than alloy 2205 for these test conditions. These data suggest alloy 2003 could be appropriate for some $288^{\circ} \mathrm{C}$ nuclear power applications, whereas alloy 2205 would be limited to applications at $260^{\circ} \mathrm{C}$ and below. The higher upper service temperature of the lean grade alloy enables new applications where the standard grades would be deemed unacceptable.

\subsection{Microhardness}

As $\alpha-\alpha^{\prime}$ phase separation takes place in the ferrite phase of DSS, its hardness increases.

Microhardness testing was performed in the ferrite phase of both alloys. The replicate measurement variability within a given sample increased with increased hardening (i.e., harder materials had more scattered individual hardness measurements). Averaging several hardness measurements reduces the impact of data scatter, with the uncertainty in the average decreasing as the number of measurements is increased. A one sigma error on the average measured microhardness for a given aging condition is estimated to be approximately $\pm 5 \%$.

The averaged microhardness values were used to fit the KJMA equation in order to create a surface that describes the change in microhardness as a function of aging time and temperature. The average microhardness values and standard deviation for each specimen are included as an online supplement to this paper. The fit surfaces and the average microhardness measurement data for both alloys are shown in Figure 5. The parameters for the KJMA microhardness equation are provided in Table 6 along with the impact toughness parameters. Note that the "as-received" condition is included in the KJMA fit at an arbitrary time and temperature $\left(260^{\circ} \mathrm{C}, 0.1\right.$ hours $)$, where no change in hardness is expected. 
A graphical representation of the goodness of fit between the model and the experimental averaged data is given in Figure 6. The data are well distributed about the model prediction. The model predicts low values of microhardness relatively well, but there is increased scatter with increasing microhardness. Hardness values near $300 \mathrm{HV}$ correspond to impact toughness values near $47 \mathrm{~J}$, which are of the most engineering significance.

Comparisons of the microhardness and impact toughness datasets for both alloys show the following:

- The Avrami exponent ( $n$ ) for all cases is near a value of 0.5 (within the standard error of the KJMA fits).

- The initial microhardness $\left(\mathrm{H}_{0}\right)$ value is similar for both alloys; however, the maximum microhardness $\left(H_{\max }\right)$ for alloy 2205 is significantly higher than alloy 2003.

- For alloy 2003 , the activation energy $(\mathrm{Q})$ and pre-factor $\left(\mathrm{k}_{0}\right)$ fall within the standard error for the microhardness and impact toughness KJMA fits. This indicates that microhardness testing is equally effective in predicting the $\alpha-\alpha^{\prime}$ phase tranformation as impact toughness testing for this alloy.

- For alloy 2205, the microhardness activation energy and pre-factor are significantly less compared to 2205 impact toughness values and are significantly lower than alloy 2003.

The effect of aging time and temperature for both alloys at different levels of microhardness are shown in Figure 7. Alloy 2205 hardens more rapidly than alloy 2003. In the 40-80 year time window of interest for the commercial nuclear power industry, alloy 2003 performs better than alloy 2205.

The correlation between microhardness and impact toughness at a $20^{\circ} \mathrm{C}$ test temperature is shown in Figure 8. Impact toughness drops sharply with increasing microhardness. The upper service temperatures for both alloys as a function of component lifetime (in hot years), for hardness limits of 275 and $300 \mathrm{HV}$ to maintain a minimum impact toughness of $47 \mathrm{~J}$, are given in The $47 \mathrm{~J}$ limit is reached between 275 and $300 \mathrm{HV}$ for both alloys. Table 7. 
The microhardness upper service temperature limits are similar to the impact toughness limits presented for alloy 2003 in Table 5, but are significantly lower for alloy 2205. This indicates that alloy 2205 is hardening faster than alloy 2003 given a similar response in impact toughness. This could be due to additional phase transformations taking place in alloy 2205 , which will be discussed below.

\subsection{Atom Probe Tomography}

APT was performed on both alloys to confirm the phase transformation mechanism and to provide insight on how solute additions were partitioning between phases. Specimens aged at $427^{\circ} \mathrm{C}$ for up to 10,000 hours were analyzed using APT. The aging times and the number of ions collected at each condition are given in Table 8.

Chromium atom maps for both alloys at the various aging times are shown in Figure 9. A standardsized volume of $40 \mathrm{~nm} \times 15 \mathrm{~nm} \times 5 \mathrm{~nm}$ was removed from each data set for a one-to-one visual comparison of the $\mathrm{Cr}$ atom distributions. The $5 \mathrm{~nm}$ dimension is oriented into the page. The $\mathrm{Cr}$ distribution is fairly homogeneous at early aging times and then separates into Cr-rich (blue regions) and $\mathrm{Cr}$-poor regions with increasing aging time. The phase separation occurs earlier for alloy 2205 than alloy 2003 and is evident at 100 hours. As the material is aged longer, the $\mathrm{Cr}$-rich regions coarsen and increase in $\mathrm{Cr}$ concentration. The three dimensional reconstruction of the $\mathrm{Cr}$ atom distribution reveals an interconnected morphology of the Cr-rich phase for both alloys. This morphology indicates that phase separation is occurring through spinodal decomposition as opposed to a nucleation and growth process, where the Cr-rich phase would be expected to exhibit discrete clusters.

The difference in the $\mathrm{Cr}$ concentration in the $\alpha-\alpha^{\prime}$ phases was quantified using the Langer, Bar-On, Miller (LBM) non-linear theory of spinodal decomposition. The LBM model assumes that there are two overlapping $\mathrm{Cr}$ concentration peaks in the Cr distribution that are eventually resolved as phase 
separation becomes more pronounced. These peaks correspond to $\mathrm{Cr}$ concentrations in the $\mathrm{Cr}$ enriched $\alpha^{\prime}$ and $\mathrm{Cr}$-depleted $\alpha$ phases. The difference in the $\mathrm{Cr}$ concentration value will approach the width of the miscibility gap in the phase diagram for each alloy at $427^{\circ} \mathrm{C}$. The evolution of the differences in the $\mathrm{Cr}$ concentrations of the $\alpha$ - $\alpha^{\prime}$ phases, $\Delta_{\mathrm{Cr}}$, with aging time for both alloys is shown in Figure 10.

Initially, the difference in $\Delta_{\mathrm{Cr}}$ is small for both alloys, since the distribution of $\mathrm{Cr}$ is fairly homogenous. In the earliest regime, the $\Delta_{c r}$ in alloy 2003 has a slightly higher value than 2205 . However, by 100 hours, $\Delta_{\mathrm{Cr}}$ has nearly doubled and 2205 is showing slightly more $\mathrm{Cr}$ separation that alloy 2003 . This is consistent with the $\mathrm{Cr}$ atom maps in Figure 9, where the Cr separation is more visible for alloy 2205 after 100 hours. At 1000 and 10,000 hours, the Cr separation increases for both alloys, but is more evident for alloy 2205 and the trend is holding. The enhanced phase separation rate for alloy 2205 over 2003 is most likely due to alloying differences (higher initial $\mathrm{Cr}$, Ni, and Mo concentrations). It is interesting to note that alloy 2205 has significanly poorer impact toughness properties than alloy 2003 when aged at $427^{\circ} \mathrm{C}$ for 100 hours, yet the $\mathrm{Cr}$ separation is similar for the two alloys. This suggests that another embrittlement mechanism is present in alloy 2205, as discussed below.

\subsection{Solute Segregation}

APT analysis reveals the partitioning of solutes between the $\mathrm{Cr}$-enriched $\alpha^{\prime}$ and $\mathrm{Cr}$-depleted $\alpha$ phases. In alloy 2003 after aging for 1000 hours, Mo (1.3 times), Mn (1.4 times), and Si (1.3 times) are enriched in the $\alpha^{\prime}$ phase compared to the $\alpha$ phase. However, only Mo (2.0 times) was enriched in the Cr-enriched $\alpha^{\prime}$ phase in alloy 2205. The reason for this difference in partitioning is evident from a comparison of the atom maps for $\mathrm{Ni}, \mathrm{Mn}, \mathrm{Si}$, and $\mathrm{Cu}$ for alloys 2003 and 2205 aged at $427^{\circ} \mathrm{C}$ for 10,000 hours, shown in Figure 11. A spheroidal Ni-enriched phase at the $\alpha$ - $\alpha$ ' interface was observed in the higher $\mathrm{Ni}, \mathrm{Mo}, \mathrm{Mn}, \mathrm{Si}$, and $\mathrm{Cu}$ alloy 2205, but not in alloy 2003. This suggests that elements being rejected from the $\alpha$ or $\alpha^{\prime}$ phase form nucleation sites at the $\alpha$ - $\alpha^{\prime}$ boundary for these $\mathrm{Ni}$-enriched 
precipitates. Small 2-nm-diameter precipitates are evident after 100 hours of aging at $427^{\circ} \mathrm{C}$ and they coarsen with time. By 10,000 hours, the precipitates have an average diameter of $\sim 5 \mathrm{~nm}$ and an average composition of $40.1 \pm 0.4 \% \mathrm{Ni}, 20.8 \pm 0.3 \% \mathrm{Fe}, 19.0 \pm 0.3 \% \mathrm{Mn}, 7.8 \pm 0.8 \% \mathrm{Si}, 5.5 \pm 0.2 \%$ $\mathrm{Cr}, 4.3 \pm 0.2 \% \mathrm{Cu}$, and $1.1 \pm 0.1 \%$ Mo. Based on their composition, these Ni-rich precipitates are possibly a form of G-phase [20-22], but their identity has not been confirmed by transmission electron microscopy.

The kinetics of G-phase precipitation has been shown to correlate with Mo and C content [21]. The C content is similar for the duplex alloys; however, Mo is slightly higher ( 1 at. \%) for alloy 2205. This suggests that minor alloying difference can have significant effects on the thermal stability of these alloys. The precipitation of the Ni-enriched phase is likely responsible for additional hardening and embrittlement of alloy 2205.

\subsection{Conclusions}

The impact toughness model shows that alloy 2003 upper service temperatures are $\sim 30^{\circ} \mathrm{C}$ higher than alloy 2205 for test conditions considered. For room temperature test conditions and a minimum impact energy of $47 \mathrm{~J}$, upper service temperature predictions show that alloy 2003 may be considered for use in $288^{\circ} \mathrm{C}$ applications and standard grade alloy 2205 should be limited to $260^{\circ} \mathrm{C}$ applications This corresponds to a $\sim 7 x$ improvement in service years for alloy 2003 over alloy 2205 at $288^{\circ} \mathrm{C}$. The higher upper service temperature capability of the lean grade alloy 2003 enables new applications for DSS where the standard grade would be deemed unacceptable. Microhardness modeling confirmed the upper service temperature prediction for alloy 2003 and predicts similar KJMA parameters. Microhardness testing predicts a more conservative upper service temperature for alloy 2205 $\left(\sim 230^{\circ} \mathrm{C}\right)$ relative to impact testing $\left(\sim 260^{\circ} \mathrm{C}\right)$, but this is likely caused by the Ni-enriched precipitates observed by APT. These precipitates are suspected to contribute to both additional hardening and 
embrittlement. This suggests microhardness testing can be used in lieu of impact toughness testing for DSS alloys without Ni-enriched precipitates.

The ferrite composition of alloy 2003 and 2205 are similar, with minor alloying element differences less than 1.5 at. \%. However, alloy 2003 has a significant improvement in thermal stability over 2205 and does not form detrimental Ni-enriched precipitates over the aging conditions studied. This suggests that minor alloying differences can have significant effects on the thermal stability of these alloys. Further work to understand the role of each solute addition on thermal stability is warranted and can help optimize material performance for critical applications like nuclear power systems.

\subsection{Acknowledgements}

The Authors gratefully acknowledge the assistance of the following contributors: Ms. Kathy Powers at Oak Ridge National Laboratory for sample preparation and atom probe analysis, and Ms. Chelsea Ehlert at Rensselaer Polytechnic Institute for microhardness testing. At the Knolls Atomic Power Laboratory: Dr. Dan R. Eno for statistical analysis, and Mr. Joe Badalucco for the metallography, impact toughness and microhardness testing. Atom probe tomography research was performed as part of a user project supported by ORNL's Center for Nanophase Materials Sciences (CNMS), which is sponsored by the Scientific User Facilities Division, Office of Basic Energy Sciences, U.S. Department of Energy.

\subsection{References}

[1] Charles J. Duplex Stainless Steels - a Review after DSS '07 held in Grado. Steel Research Int. $2008 ; 79$.

[2] Data Sheet AL2003 (UNS S32003). vol. Bulletin No. 1031: Rolled Alloys, 2007. 
[3] Duplex stainless steels, Microstructure, properties and applicaitons. Abington, Cambridge, England: Abington Publishing, 1997.

[4] Tucker JD, Young GA, Eno DR. Thermal Embrittlement of a Lean Grade of Duplex Stainless Steel: Alloy 2003. Solid State Phenomena 2011;172-174:331.

[5] Young GA, Tucker JD, Lewis N, Plesko E, Sander P. Assessment of Lean Grade Duplex Stainless Steels for Nuclear Power Applications. In: Busby JT, Editor. 15th International Conference on Environmental Degradation of Materials in Nuclear Power Systems - Water Reactors. Colorado Springs, CO: TMS, 2011. p.2369.

[6] ASTM Standard A751, 2008. Standard Test Methods, Practices, and Terminology for Chemical Analysis of Steel Products West Conshohocken, PA: ASTM International, 2008.

[7] ASTM Standard E1019, 2008. Standard Test Methods for Determination of Carbon, Sulfur, Nitrogen, and Oxygen in Steel, Iron, Nickel, and Cobalt Alloys by Various Combustion and Fusion Techniques. West Conshohocken, PA: ASTM International, 2008.

[8] ASTM Standard E23, 2007a. Standard Test Methods for Notched Bar Impact Testing of Metallic Materials West Conshohocken, PA: ASTM International, 2007.

[9] ASTM Standard E384, 2010e2. Standard Test Method for Knoop and Vickers Hardness of Materials. West Conshohocken, PA: ASTM International, 2010.

[10] Miller MK, Russell KF, Thompson K, Alvis R, Larson DJ. Review of Atom Probe FIB-based Specimen Preparation Methods. Microscopy and Microanalysis 2007;13:428.

[11] Kolmogorov A. A statistical theory for the recrystallization of metals. Akad. nauk SSSR, Izv., Ser. Matem 1937;1.

[12] Johnson W, Mehl R. Reaction kinetics in processes of nucleation and growth. Trans AIME $1939 ; 135$.

[13] Avrami M. Kinetics of Phase Change. I: General Theory. J. Chem. Phys. 1939;7.

[14] Avrami M. Kinetics of Phase Change. II: Transformation-Time Relations for Random Distribution of Nuclei. J. Chem. Phys. 1940;8. 
[15] Avrami M. Kinetics of Phase Change. III: Granulation, Phase Change an Microstructures. J. Chem. Phys. 1941;9.

[16] Sun NX, Liu XD, Lu K. An explanation to the anomalous Avrami exponent. Scripta Materialia 1995;34:1201.

[17] Hetherington MG, Hyde JM, Miller MK, Smith GDW. Surface Science 1991;246:304.

[18] Langer JS, Bar-on M, Miller HD. Physical Review Letters A 1975;11.

[19] Criado JM, Ortega A. Non-Isothermal Crystallization Kinetics of Metal Glasses: Simulataneous Determination of Both the Activation Energy and the Exponent $n$ of the JMA Kinetic Law. Acta Met. 1987;35:1715.

[20] Danoix F, Auger P. Atom Probe Studies of the Fe-Cr System and Stainless Steels Aged at Intermediate Temperatures: A Review. Materials Characterization 2000;44:177.

[21] Chung HM, Chopra OK. Kinetics and mechanism of thermal aging embrittlement of duplex stainless steels. In: Theus GJ, Weeks JR, editors. Environmental Degradation of Materials in Nuclear Power Systems - Water Reactors, 1988. p.359.

[22] Pareige C, Novy S, Saillet S, Akamatsu M, Pareige P. Atomic Scale Study of Phase Transformation in Long Term Thermally Aged Duplex Stainless Steels: Relation Between Microstructure and Properties. Fontevraud 7, 2010. 


\section{Figure Captions}

Figure 1. Charpy V-notch impact toughness data for alloy 2003 (left) and 2205 (right) aged at $427^{\circ} \mathrm{C}$.

Figure 2. Charpy V-notch impact toughness surface fit at $20^{\circ} \mathrm{C}$ test temperature for alloy 2003 (left) and 2205 (right).

Figure 3. Impact toughness model fit to experimental data at $20^{\circ} \mathrm{C}$ test temperature.

Figure 4. Charpy V-notch impact toughness TTT curves at $20^{\circ} \mathrm{C}$ test temperature for alloy 2003 (left) and 2205 (right).

Figure 5. Microhardness surface fit and averaged microhardness data for alloy 2003 (left) and 2205 (right).

Figure 6. Microhardness model fit to experimental data.

Figure 7. Microhardness data curves for alloy 2003 (left) and 2205 (right). The hardness values are Vicker's microhardness.

Figure 8. Correlation between microhardness and impact toughness at a $20^{\circ} \mathrm{C}$ test temperature.

Figure 9. APT Cr maps for alloy 2003 (left) and 2205 (right) aged at $427^{\circ} \mathrm{C}$ for different times. Volume imaged is $40 \mathrm{~nm} \times 15 \mathrm{~nm} \times 5 \mathrm{~nm}$ (into the page).

Figure 10. LBM analysis showing separation between the Cr-enriched and Cr-depleted phases when aged at $427^{\circ} \mathrm{C}$.

Figure 11. APT Ni, Mn, Si, and Cu atom maps for alloy 2003 (left) and 2205 (right) aged at $427^{\circ} \mathrm{C}$ $\left(427^{\circ} \mathrm{C}\right)$ for 10,000 hours. Volume imaged is $40 \mathrm{~nm} \times 15 \mathrm{~nm} \times 5 \mathrm{~nm}$ (into the page). 
Alloy 2003

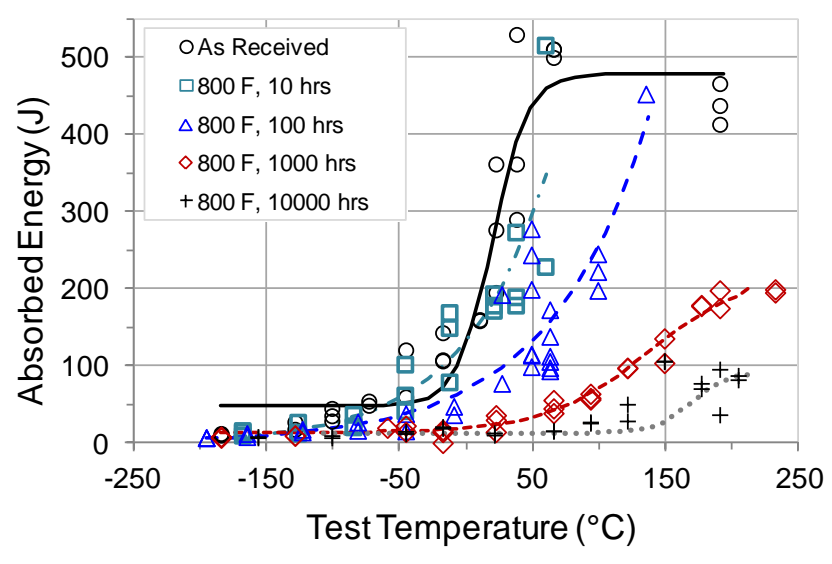

Alloy 2205

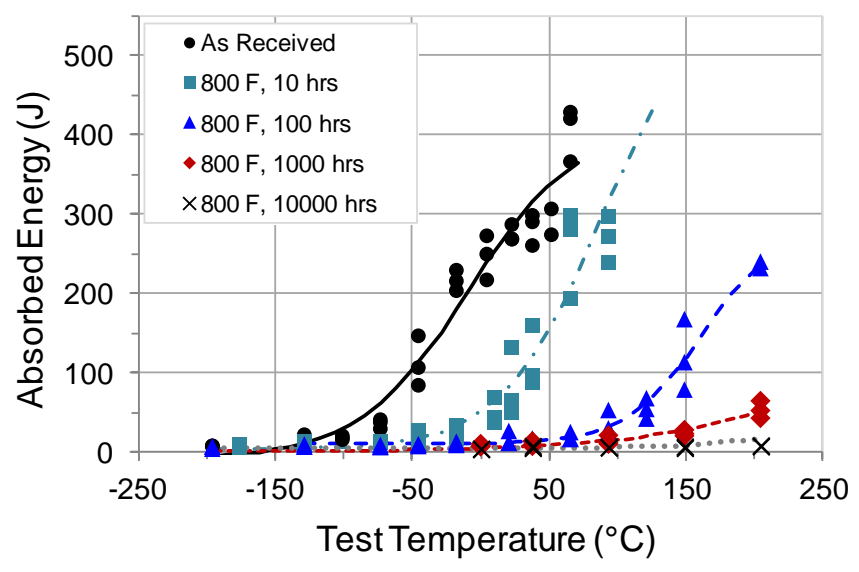

Figure 1. Charpy V-notch impact toughness data for alloy 2003 (left) and 2205 (right) aged at $427^{\circ} \mathrm{C}$. 
Alloy 2003

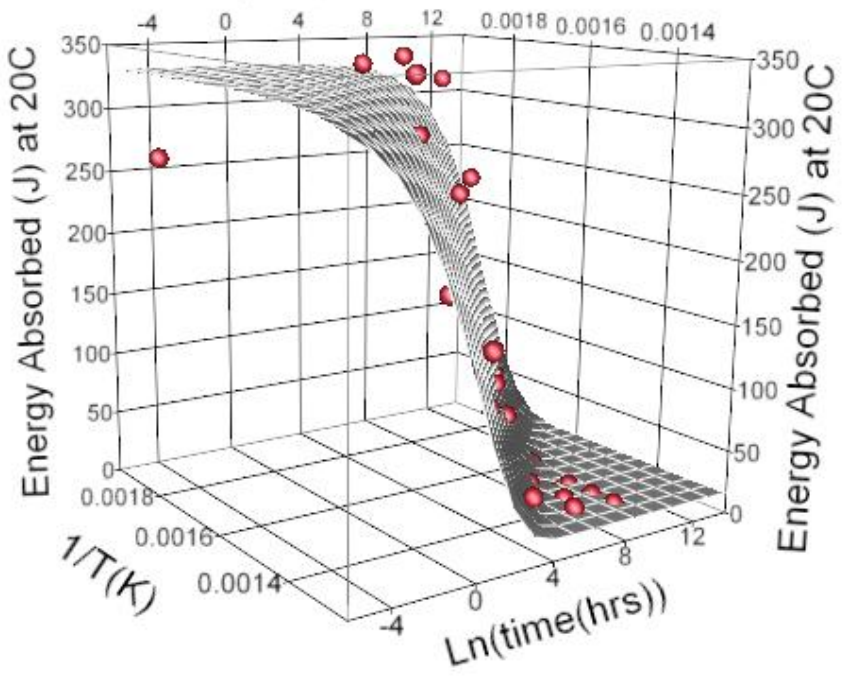

Alloy 2205

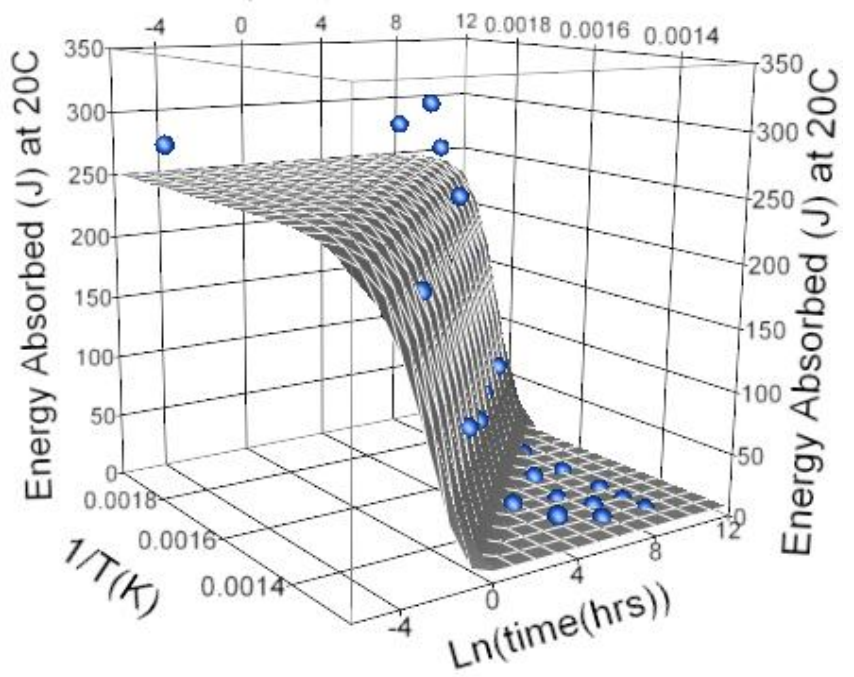

Figure 2. Charpy V-notch impact toughness surface fit at $20^{\circ} \mathrm{C}$ test temperature for alloy 2003 (left) and 2205 (right). 


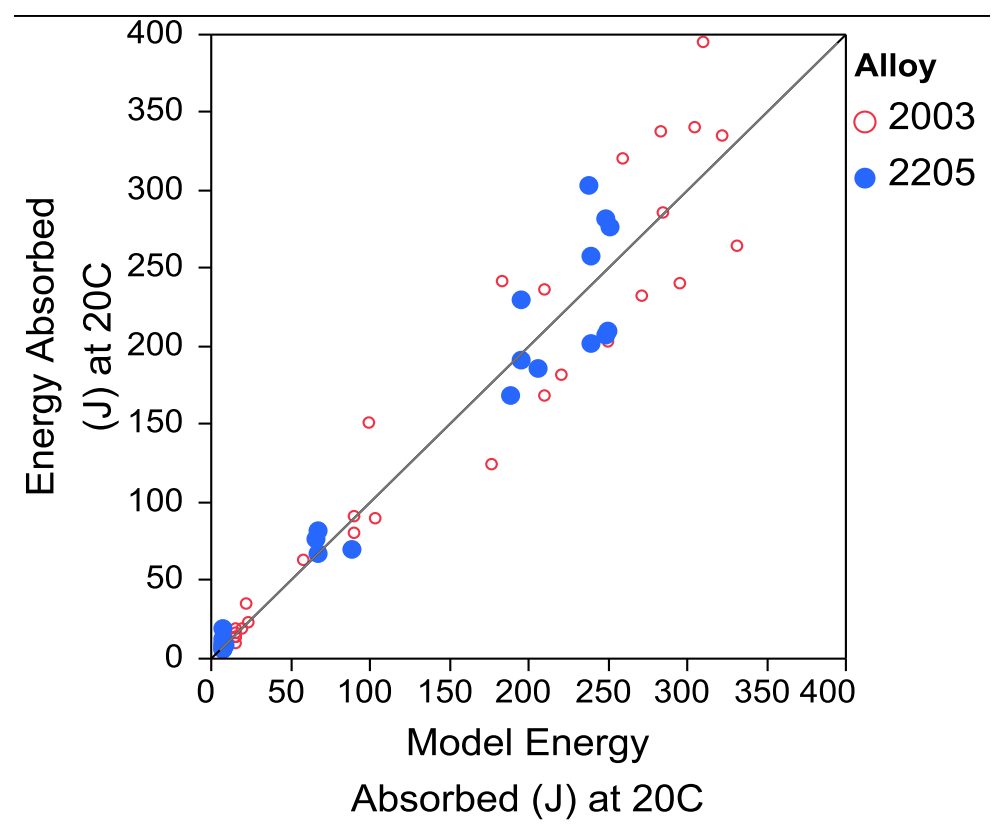

Figure 3. Impact toughness model fit to experimental data at $20^{\circ} \mathrm{C}$ test temperature. 

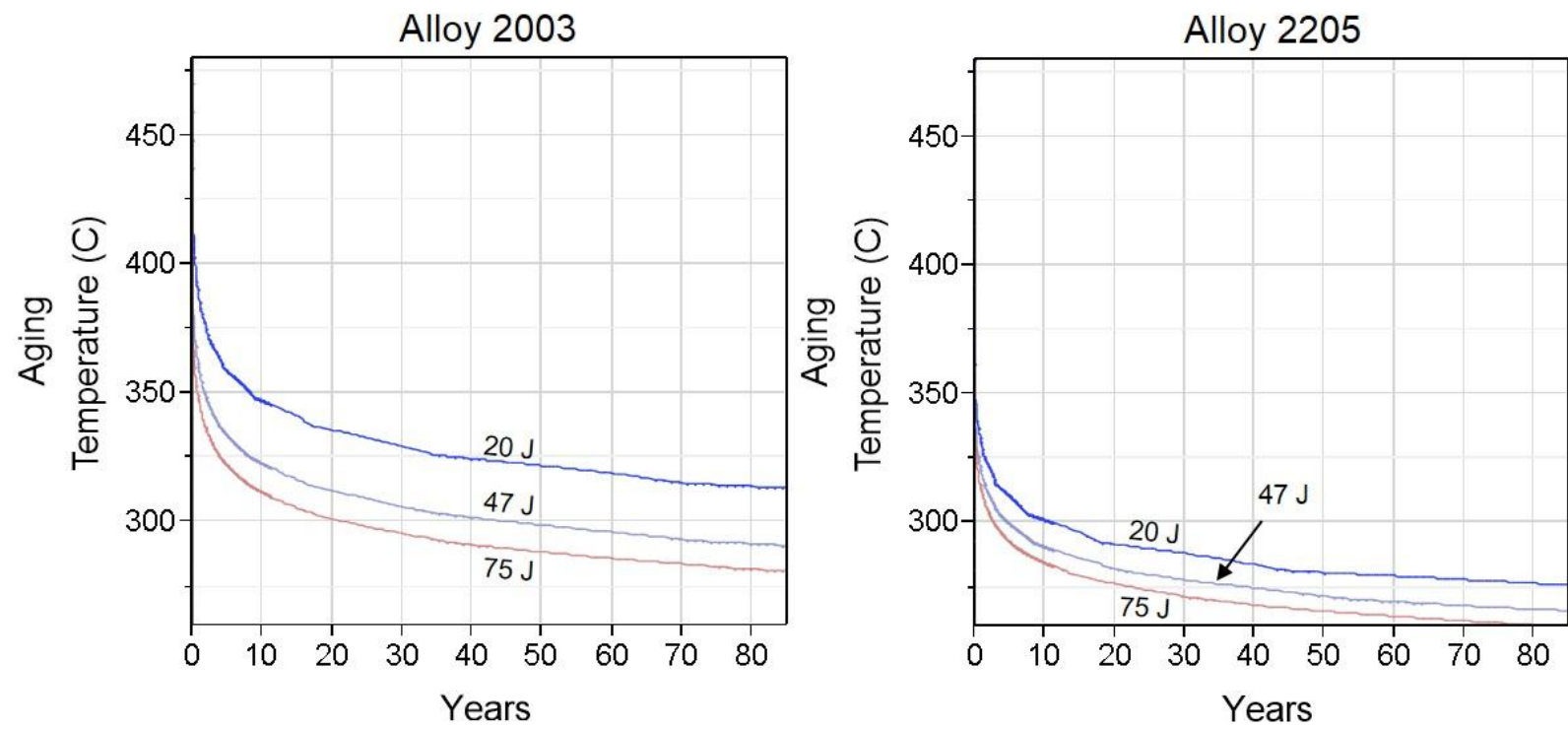

Figure 4. Charpy V-notch impact toughness TTT curves at $20^{\circ} \mathrm{C}$ test temperature for alloy 2003 (left) and 2205 (right). 

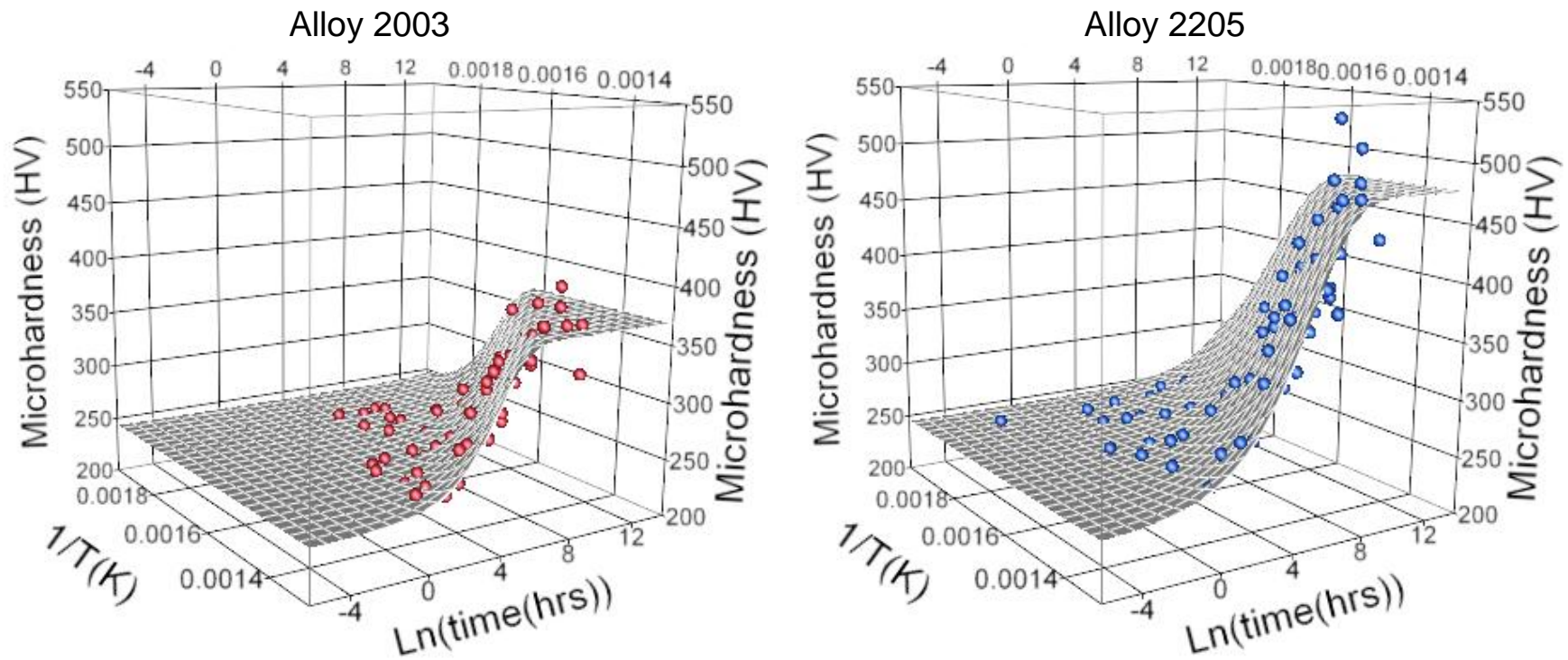

Figure 5. Microhardness surface fit and averaged microhardness data for alloy 2003 (left) and 2205 (right). 


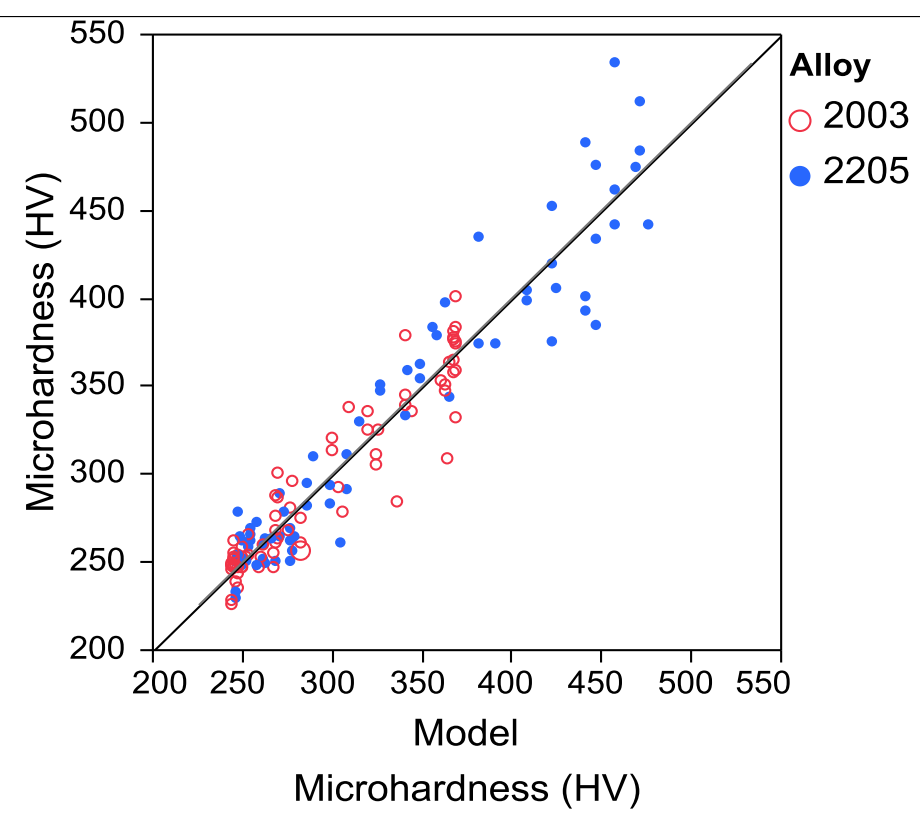

Figure 6. Microhardness model fit to experimental data. 
Alloy 2003

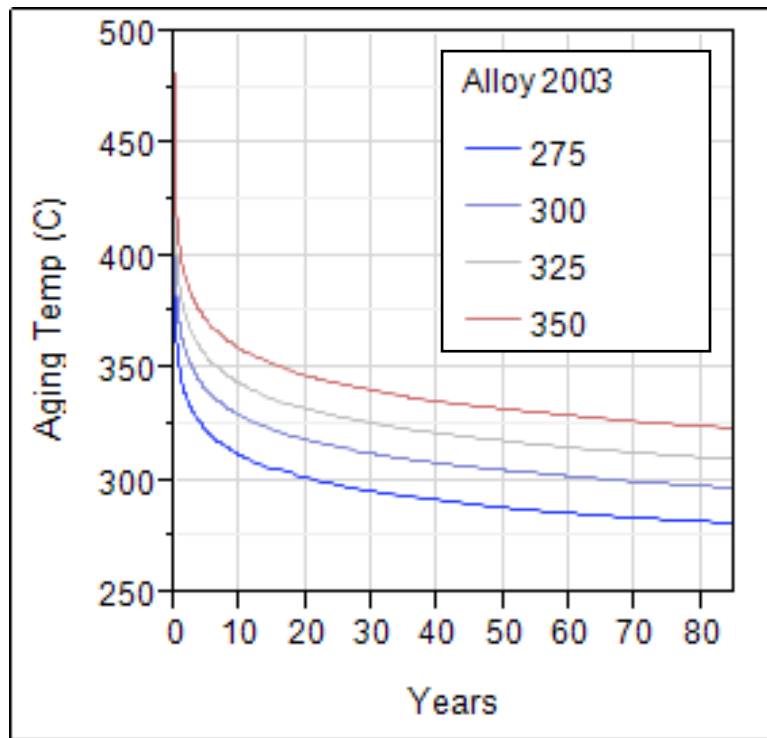

Alloy 2205

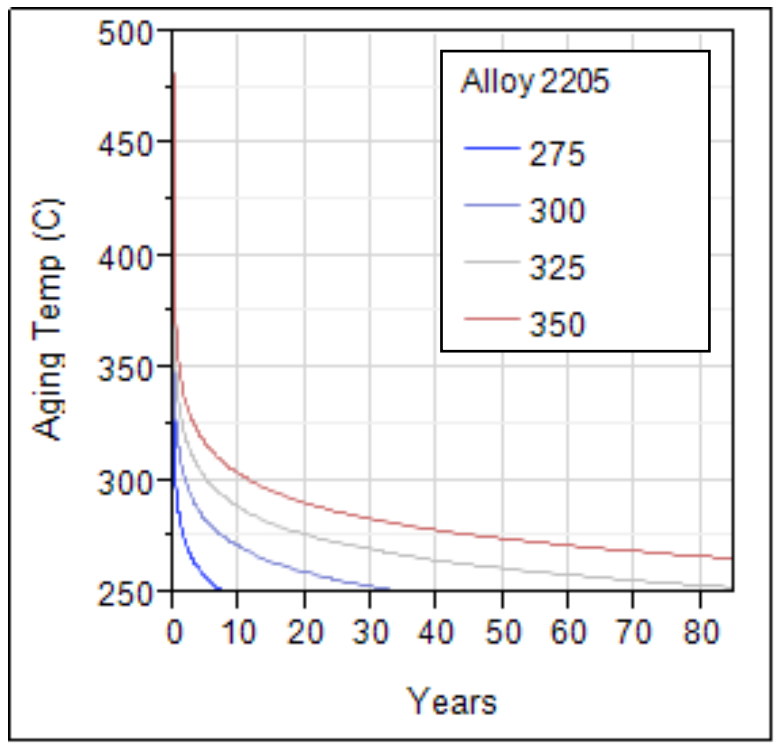

Figure 7. Microhardness data curves for alloy 2003 (left) and 2205 (right). The hardness values are Vicker's microhardness. 


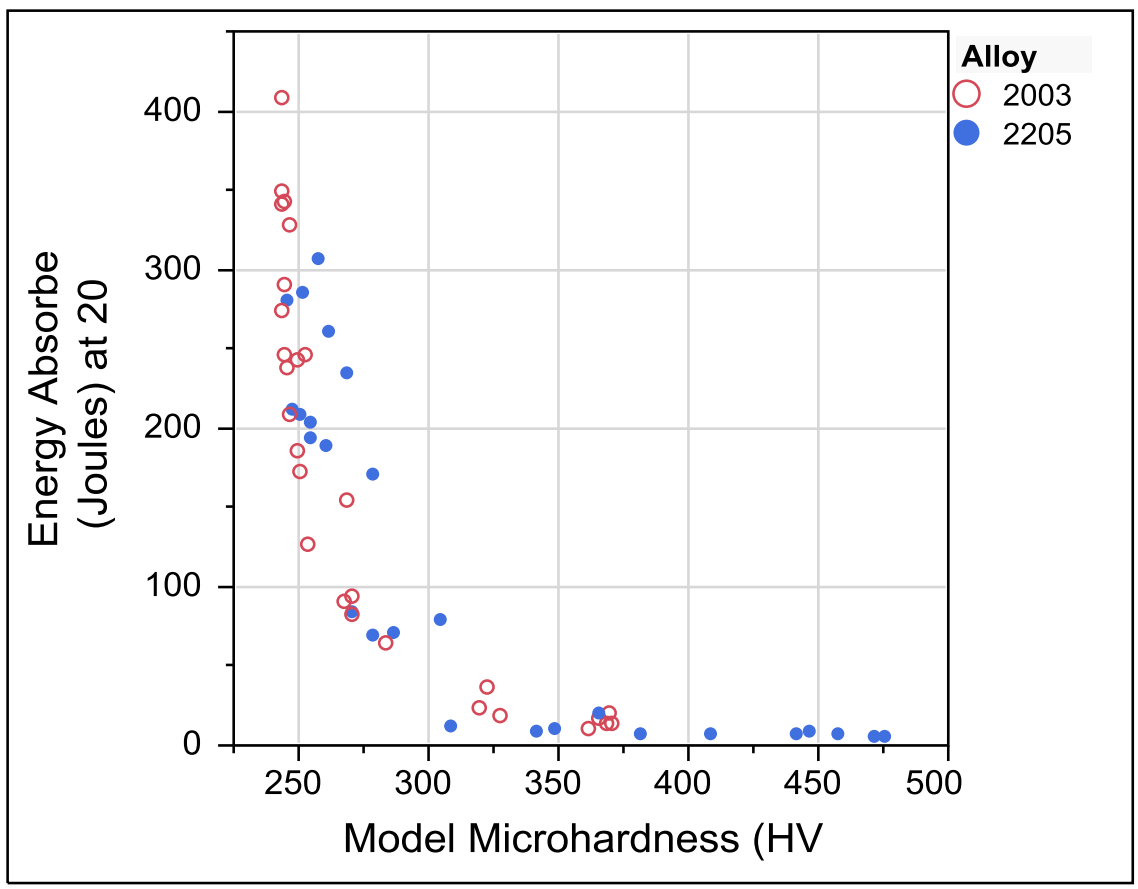

Figure 8. Correlation between microhardness and impact toughness at a $20^{\circ} \mathrm{C}$ test temperature. 


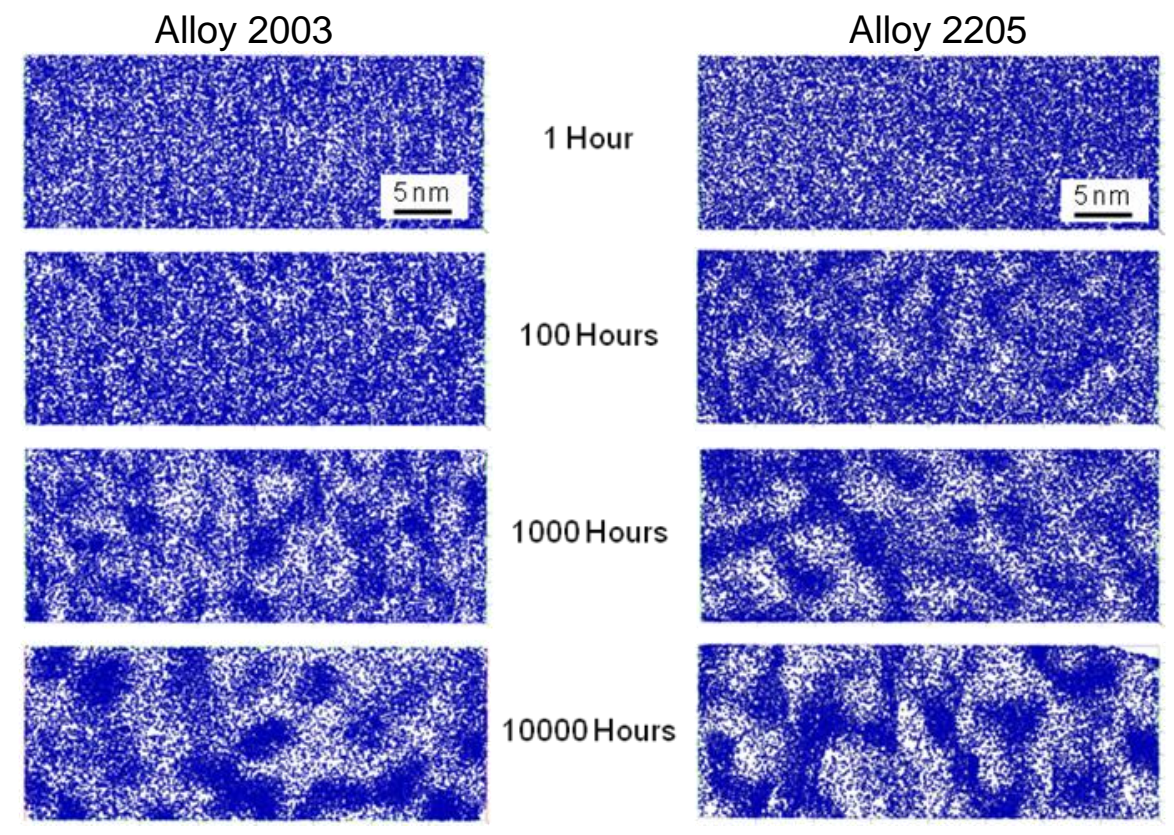

Figure 9. APT $\mathrm{Cr}$ maps for alloy 2003 (left) and 2205 (right) aged at $427^{\circ} \mathrm{C}$ for different times. Volume imaged is $40 \mathrm{~nm} \times 15 \mathrm{~nm} \times 5 \mathrm{~nm}$ (into the page). 


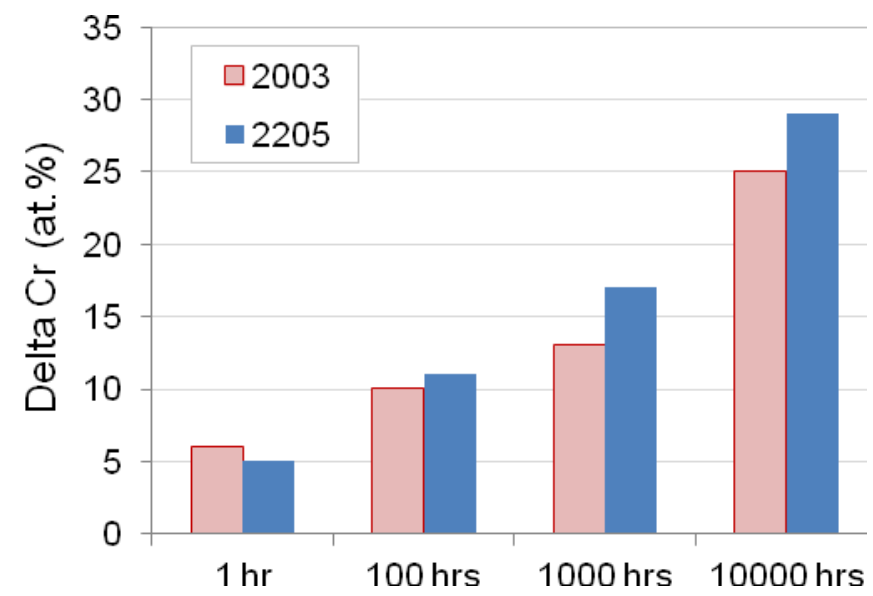

Figure 10. LBM analysis showing separation between the $\mathrm{Cr}$-enriched and $\mathrm{Cr}$-depleted phases when aged at $427^{\circ} \mathrm{C}$ 


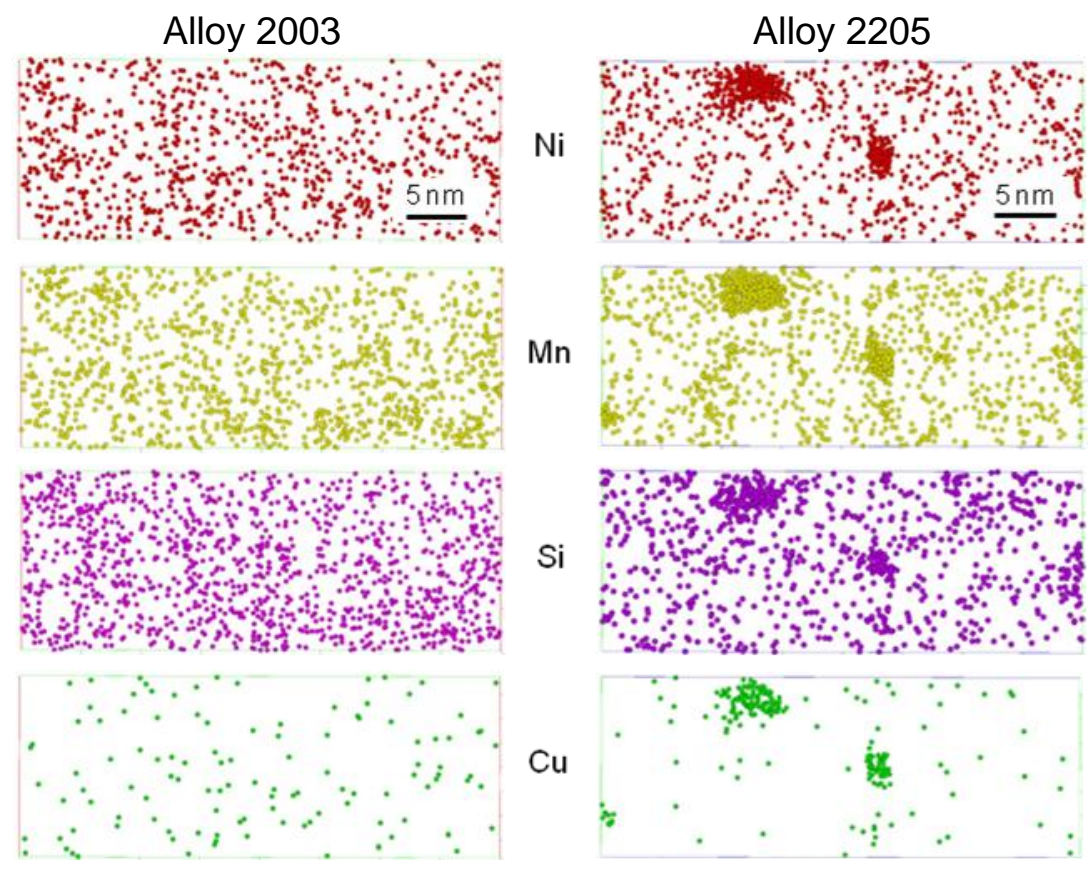

Figure 11. APT Ni, Mn, Si, and Cu atom maps for alloy 2003 (left) and 2205 (right) aged at $427^{\circ} \mathrm{C}$ $\left(427^{\circ} \mathrm{C}\right.$ ) for 10,000 hours. Volume imaged is $40 \mathrm{~nm} \times 15 \mathrm{~nm} \times 5 \mathrm{~nm}$ (into the page). 
Table 1. Duplex Stainless Steel Alloy Compositions (wt. \%)

\begin{tabular}{|l|c|c|c|c|c|c|c|c|c|c|c|c|c|c|}
\hline Alloy & Heat & $\mathrm{Fe}$ & $\mathrm{Cr}$ & $\mathrm{Ni}$ & $\mathrm{Mo}$ & $\mathrm{Mn}$ & $\mathrm{Si}$ & $\mathrm{N}$ & $\mathrm{C}$ & $\mathrm{S}$ & $\mathrm{P}$ & $\mathrm{Cu}$ & $\mathrm{Al}$ & $\mathrm{Co}$ \\
\hline 2003 & 511794 & Bal. & 21.42 & 3.70 & 1.75 & 1.22 & 0.37 & 0.180 & 0.010 & 0.0008 & 0.024 & $0.13^{*}$ & $0.01^{*}$ & $\mathrm{NR}$ \\
2205 & 827616 & Bal. & 22.44 & 5.69 & 3.11 & 1.80 & 0.42 & 0.17 & 0.020 & 0.0004 & 0.028 & 0.43 & $\mathrm{NR}$ & 0.33 \\
\hline
\end{tabular}

NR=Not Reported

*value from independent chemistry analysis 
Table 2. Alloy 2003 test matrix

\begin{tabular}{|c|c|c|c|c|c|c|c|c|c|c|c|c|}
\hline \multirow{2}{*}{$\begin{array}{c}\text { Temperature } \\
\text { oC }\end{array}$} & \multicolumn{12}{|c|}{ Aging Times (Hours) } \\
\hline & 1 & 5 & 10 & 50 & 100 & 200 & 500 & 1000 & 2000 & 4000 & 5000 & 10000 \\
\hline $\begin{array}{l}538 \\
510\end{array}$ & $\mathrm{H}$ & $\mathrm{H}$ & $\mathrm{CVN}, \mathrm{H}$ & $\mathrm{H}$ & $\mathrm{CVN}, \mathrm{H}$ & $\mathrm{H}$ & $\mathrm{H}$ & $\mathrm{H}$ & & & & \\
\hline 482 & $\mathrm{H}$ & $\mathrm{H}$ & $\mathrm{CVN}, \mathrm{H}$ & $\mathrm{H}$ & $\mathrm{CVN}, \mathrm{H}$ & $\mathrm{H}$ & $\mathrm{H}$ & $\mathrm{CVN}, \mathrm{H}$ & & $\mathrm{H}$ & & $\mathrm{CVN}, \mathrm{H}$ \\
\hline 454 & & $\mathrm{H}$ & & $\mathrm{H}$ & & $\mathrm{H}$ & & & $\mathrm{CVN}, \mathrm{H}$ & & & $\mathrm{CVN}, \mathrm{H}$ \\
\hline 427 & $\mathrm{H}$ & $\mathrm{H}$ & CVN,H & $\mathrm{H}$ & $\mathrm{CVN}, \mathrm{H}$ & $\mathrm{H}$ & $\mathrm{H}$ & $\mathrm{CVN}, \mathrm{H}$ & $\mathrm{H}$ & & $\mathrm{CVN}, \mathrm{H}$ & $\mathrm{CVN}, \mathrm{H}$ \\
\hline 385 & & $\mathrm{H}$ & CVN,H & $\mathrm{H}$ & $\mathrm{CVN}, \mathrm{H}$ & $\mathrm{H}$ & $\mathrm{H}$ & $\mathrm{CVN}, \mathrm{H}$ & $\mathrm{CVN}, \mathrm{H}$ & & $\mathrm{H}$ & $\mathrm{CVN}, \mathrm{H}$ \\
\hline 343 & & & & & $\mathrm{CVN}, \mathrm{H}$ & & $\mathrm{H}$ & $\mathrm{CVN}, \mathrm{H}$ & $\mathrm{CVN}, \mathrm{H}$ & & & $\mathrm{CVN}, \mathrm{H}$ \\
\hline 316 & & & & & $\mathrm{CVN}, \mathrm{H}$ & & $\mathrm{H}$ & $\mathrm{CVN}, \mathrm{H}$ & $\mathrm{CVN}, \mathrm{H}$ & & & $\mathrm{CVN}, \mathrm{H}$ \\
\hline 288 & & & & & $\mathrm{CVN}, \mathrm{H}$ & & $\mathrm{H}$ & $\mathrm{CVN}, \mathrm{H}$ & $\mathrm{CVN}, \mathrm{H}$ & & & CVN,H \\
\hline
\end{tabular}

CVN = impact toughness $\mathrm{H}=$ microhardness 
Table 3. Alloy 2205 test matrix

\begin{tabular}{|c|c|c|c|c|c|c|c|c|c|c|c|}
\hline \multirow{2}{*}{$\begin{array}{c}\text { Temperature } \\
\text { oc }\end{array}$} & \multicolumn{11}{|c|}{ Aging Times (Hours) } \\
\hline & 1 & 5 & 10 & 50 & 100 & 200 & 500 & 1000 & 2000 & 3000 & 10000 \\
\hline $\begin{array}{l}538 \\
510\end{array}$ & $\mathrm{H}$ & $\mathrm{H}$ & $\mathrm{H}$ & $\mathrm{H}$ & $\mathrm{H}$ & $\mathrm{H}$ & $\mathrm{H}$ & $\mathrm{H}$ & & & \\
\hline 482 & $\mathrm{H}$ & $\mathrm{H}$ & $\mathrm{H}$ & $\mathrm{H}$ & $\mathrm{CVN}, \mathrm{H}$ & $\mathrm{H}$ & $\mathrm{H}$ & $\mathrm{CVN}, \mathrm{H}$ & & $\mathrm{H}$ & $\mathrm{CVN}, \mathrm{H}$ \\
\hline 454 & & $\mathrm{H}$ & & $\mathrm{H}$ & & $\mathrm{H}$ & & & $\mathrm{CVN}, \mathrm{H}$ & & $\mathrm{CVN}, \mathrm{H}$ \\
\hline 427 & $\mathrm{CVN}, \mathrm{H}$ & & $\mathrm{CVN}, \mathrm{H}$ & & $\mathrm{CVN}, \mathrm{H}$ & $\mathrm{H}$ & $\mathrm{H}$ & $\mathrm{CVN}, \mathrm{H}$ & & $\mathrm{H}$ & $\mathrm{CVN}, \mathrm{H}$ \\
\hline 385 & $\mathrm{H}$ & $\mathrm{H}$ & $\mathrm{H}$ & $\mathrm{H}$ & $\mathrm{CVN}, \mathrm{H}$ & $\mathrm{H}$ & $\mathrm{H}$ & $\mathrm{H}$ & $\mathrm{CVN}, \mathrm{H}$ & $\mathrm{H}$ & $\mathrm{CVN}, \mathrm{H}$ \\
\hline 343 & $\mathrm{H}$ & & $\mathrm{H}$ & & CVN,H & & $\mathrm{H}$ & CVN,H & $\mathrm{H}$ & & $\mathrm{CVN}, \mathrm{H}$ \\
\hline 316 & $\mathrm{H}$ & & $\mathrm{H}$ & & $\mathrm{CVN}, \mathrm{H}$ & & $\mathrm{H}$ & $\mathrm{CVN}, \mathrm{H}$ & $\mathrm{H}$ & & $\mathrm{CVN}, \mathrm{H}$ \\
\hline 288 & & & $\mathrm{H}$ & & $\mathrm{CVN}, \mathrm{H}$ & & & $\mathrm{CVN}, \mathrm{H}$ & $\mathrm{H}$ & & $\mathrm{CVN}, \mathrm{H}$ \\
\hline 260 & & & & & $\mathrm{CVN}, \mathrm{H}$ & & & $\mathrm{CVN}, \mathrm{H}$ & $\mathrm{H}$ & & $\mathrm{CVN}, \mathrm{H}$ \\
\hline
\end{tabular}

CVN = impact toughness $\mathrm{H}=$ microhardness 
Table 4. KJMA parameters and approximate standard error when fit to impact toughness data at $20^{\circ} \mathrm{C}$ test temperature.

\begin{tabular}{|c|c|c|}
\hline Parameter & Alloy 2003 & Alloy 2205 \\
\hline $\ln \left(\mathrm{k}_{0}\right)$ & $28.3 \pm 3.6$ & $34.6 \pm 2.6$ \\
$\mathrm{Q}(\mathrm{kJ} / \mathrm{mol})$ & $188.1 \pm 19.3$ & $212.3 \pm 13.5$ \\
$\mathrm{E}_{0}(\mathrm{~J})$ & $340 \pm 27$ & $255 \pm 12$ \\
$\mathrm{n}$ & $0.5 \pm 0.1$ & $0.7 \pm 0.2$ \\
$\mathrm{E}_{\min }(\mathrm{J})$ & $16 \pm 15$ & $8 \pm 8$ \\
\hline
\end{tabular}


Table 5. Upper service temperature $\left({ }^{\circ} \mathrm{C}\right)$ to maintain $47 \mathrm{~J}$ impact toughness at $20^{\circ} \mathrm{C}$ with aging time.

\begin{tabular}{|c|c|c|c|}
\hline Time (years) & Alloy 2003 & Alloy 2205 & $\Delta \mathrm{T}$ \\
\hline 40 & $304^{\circ} \mathrm{C}$ & $275^{\circ} \mathrm{C}$ & $29^{\circ} \mathrm{C}$ \\
50 & $301^{\circ} \mathrm{C}$ & $272^{\circ} \mathrm{C}$ & $29^{\circ} \mathrm{C}$ \\
60 & $298^{\circ} \mathrm{C}$ & $271^{\circ} \mathrm{C}$ & $27^{\circ} \mathrm{C}$ \\
70 & $296^{\circ} \mathrm{C}$ & $268^{\circ} \mathrm{C}$ & $28^{\circ} \mathrm{C}$ \\
80 & $294^{\circ} \mathrm{C}$ & $267^{\circ} \mathrm{C}$ & $27^{\circ} \mathrm{C}$ \\
\hline
\end{tabular}


Table 6. KJMA parameters and approximate standard error for microhardness and impact toughness data.

\begin{tabular}{|c|c|c|c|c|}
\hline Parameter & $\begin{array}{c}\text { Alloy 2003 } \\
\text { Microhardness }\end{array}$ & $\begin{array}{c}\text { Alloy 2003 } \\
\text { Impact Toughness }\end{array}$ & $\begin{array}{c}\text { Alloy 2205 } \\
\text { Microhardness }\end{array}$ & $\begin{array}{c}\text { Alloy 2205 } \\
\text { Impact Toughness }\end{array}$ \\
\hline $\ln \left(\mathrm{k}_{0}\right)$ & $25.5 \pm 2.2$ & $28.3 \pm 3.6$ & $18.1 \pm 2.1$ & $34.6 \pm 2.6$ \\
$\mathrm{Q}(\mathrm{kJ} / \mathrm{mol})$ & $189.1 \pm 13.2$ & $188.1 \pm 19.3$ & $147.0 \pm 12.2$ & $212.3 \pm 13.5$ \\
$\mathrm{H}_{0}(\mathrm{HV}) / \mathrm{E}_{0}(\mathrm{~J})$ & $244 \pm 4$ & $340 \pm 27$ & $246 \pm 7$ & $255 \pm 12$ \\
$\mathrm{n}$ & $0.6 \pm 0.1$ & $0.5 \pm 0.1$ & $0.4 \pm 0.1$ & $0.7 \pm 0.2$ \\
$\mathrm{H}_{\max }(\mathrm{HV}) / \mathrm{E}_{\min }(\mathrm{J})$ & $371 \pm 5$ & $16 \pm 15$ & $477 \pm 15$ & $8 \pm 8$ \\
\hline
\end{tabular}


Table 7. Upper service temperature prediction with hardness value.

\begin{tabular}{|c|c|c|c|c|c|c|}
\hline $\begin{array}{c}\text { Microhardness } \\
\text { Time (years) }\end{array}$ & $\begin{array}{c}275 \mathrm{HV} \\
\text { Alloy 2003 }\end{array}$ & $\begin{array}{c}275 \mathrm{HV} \\
\text { Alloy } 2205\end{array}$ & $\Delta \mathrm{T}$ & $\begin{array}{c}300 \mathrm{HV} \\
\text { Alloy 2003 }\end{array}$ & $\begin{array}{c}300 \mathrm{HV} \\
\text { Alloy 2205 }\end{array}$ & $\Delta \mathrm{T}$ \\
\hline 40 & $293^{\circ} \mathrm{C}$ & $227^{\circ} \mathrm{C}$ & $66^{\circ} \mathrm{C}$ & $309^{\circ} \mathrm{C}$ & $249^{\circ} \mathrm{C}$ & $60^{\circ} \mathrm{C}$ \\
50 & $289^{\circ} \mathrm{C}$ & $224^{\circ} \mathrm{C}$ & $65^{\circ} \mathrm{C}$ & $306^{\circ} \mathrm{C}$ & $246^{\circ} \mathrm{C}$ & $60^{\circ} \mathrm{C}$ \\
60 & $287^{\circ} \mathrm{C}$ & $221^{\circ} \mathrm{C}$ & $66^{\circ} \mathrm{C}$ & $303^{\circ} \mathrm{C}$ & $243^{\circ} \mathrm{C}$ & $60^{\circ} \mathrm{C}$ \\
70 & $285^{\circ} \mathrm{C}$ & $219^{\circ} \mathrm{C}$ & $66^{\circ} \mathrm{C}$ & $301^{\circ} \mathrm{C}$ & $241^{\circ} \mathrm{C}$ & $60^{\circ} \mathrm{C}$ \\
80 & $283^{\circ} \mathrm{C}$ & $217^{\circ} \mathrm{C}$ & $66^{\circ} \mathrm{C}$ & $299^{\circ} \mathrm{C}$ & $239^{\circ} \mathrm{C}$ & $60^{\circ} \mathrm{C}$ \\
\hline
\end{tabular}


Table 8. Test matrix of APT specimens and atoms collected

\begin{tabular}{|c|c|c|}
\hline $\begin{array}{c}\text { Aging Time } \\
\text { (Hours) }\end{array}$ & $\begin{array}{c}\text { Alloy 2003 } \\
\text { \# of lons } \\
\text { (Millions) }\end{array}$ & $\begin{array}{c}\text { Alloy 2205 } \\
\text { \# of lons } \\
\text { (Millions) }\end{array}$ \\
\hline 1 & 5.3 & 12.9 \\
100 & 6 & 1.6 \\
1000 & 6.2 & 2.8 \\
10000 & 1.1 & 3.8 \\
\hline
\end{tabular}

